九州大学学術情報リポジトリ

Kyushu University Institutional Repository

\title{
Studies on Axial Deviation of Hole in Deep Machine-Boring of Wood
}

Ohuchi, Takeshi

Faculty of Agriculture, Kyushu Unviersity

Suzuki, Nobuhiko

Graduate School of Bioresource and Bioenvironmental Sciences, Kyushu Unviersity

Murase, Yasuhide

Faculty of Agriculture, Kyushu Unviersity

https://doi.org/10.5109/4648

出版情報: 九州大学大学院農学研究院紀要. 50 (2)，pp.353-362，2005-10-01. Faculty of Agriculture, Kyushu University

バージョン：

権利関係 : 


\title{
Studies on Axial Deviation of Hole in Deep Machine-Boring of Wood
}

\section{Takeshi OHUCHI*, Nobuhiko SUZUKI ${ }^{1}$ and Yasuhide MURASE}

\author{
Laboratory of Wood Material Technology, Division of Biomaterial Science, \\ Department of Forest and Forest Products Sciences, \\ Faculty of Agriculture,Kyushu University, \\ Fukuoka 812-8581, Japanese \\ (Received June 30, 2005 and accepted July 26, 2005)
}

\begin{abstract}
Many deep holes for bolt joints are often required for construction using a large dimension structural glued laminated timber. In deep machine-boring of this type of timber, axial deviation of the hole frequently occurs, and causes difficulty in the bolt joint operation. Therefore, the development of machine boring which prevents axial deviation of hole is important. The objective of this study was to obtain basic information on axial deviation of the hole in the deep machine-boring of wood. In this experiment, the effects of knots and bit wear on axial deviation of the hole were examined, and acoustic emission (AE) and power consumption were also measured during the boring process. The main results obtained are as follows: Axial deviation of hole was affected by the annual rings, and became larger with increasing bit wear. In workpieces which had a loose knot, all deep holes deviated in the direction of the loose knot. The average value of both the $\mathrm{AE}$ and power consumption became larger with increasing feed per revolution. For the other hand, the average value of the $\mathrm{AE}$ were almost unaffected by bit wear, and the average value of power consumption increased slightly by bit wear. A correspondence between axial deviation of hole and the $\mathrm{AE}$ or power consumption was not recognized.
\end{abstract}

\section{INTRODUCTION}

Recently, large dimension structural glued laminated timber has been widely introduced for many buildings. Bolt joints have been chiefly adopted in these structural materials. In machine-boring of bolt joints, it is demanded to be able to process many borings in not only high accuracy but also speedy. In some factories, the introduction of an automatic boring-machine or the robot that replaces workers who bore by hand had been attempted. However, even when boring processes are performed with these machines, axial deviation of hole frequently occurs. In addition, a problem that joint positions become disagreements occurs. Therefore, the development of machine-boring which prevents axial deviation of the hole is greatly needed.

A technique for monitoring the wood machining process is important for the automation and automating. Acoustic emission (AE) is one method used as a monitoring technique, and is promising for the monitoring of chip formation (Kato and R. L. Lemaster, 1991; Sadanari et al., 1991), tool wear (Dornfeld and R. L. Lemaster, 1981; Murase et al., 1988; Tanaka et al., 1992), and surface roughness (Zhao et al., 1993;

\footnotetext{
1 Laboratory of Wood Material Technology, Division of Biomaterial Science, Department of Forest and Forest Products Sciences, Graduate School of Bioresource and Bioenvironmental Sciences, Kyushu University, Japanese.

* Corresponding author (E-mail: tohuchi@agr.kyushu-u.ac.jp)
} 
Aguilera et al., 2001). However, these target AE generated in the planing and sanding, the investigation on the $\mathrm{AE}$ generated in the machine-boring of wood is hardly conducted.

In this study, the objective was to obtain the basic information on axial deviation of the hole in the deep machine-boring of wood. In this experiment, the effects of knots and bit wear on axial deviation of the hole were examined and the acoustic emission (AE) and power consumption were also measured during the boring process.

\section{MATERIALS AND METHODS}

\section{Testing machine}

The deep boring-machine apparatus used in this test is shown in Figure 1 (Ohuchi et $a l ., 2003$ ). The workpiece on the stage driven by a pulse motor was fixed using a vise in this figure. A mechanism of the testing machine is to perform boring by sending the workpiece to a bit that is installed in chuck of spindle point of the motor. The feed speed and moving distance of the stage can be adjusted by controlling the pulse motor. An $\mathrm{AE}$ transducer was mounted on the side of the vise with a magnet holder, and silicon grease was spread between the vise and the $\mathrm{AE}$ transducer. The output signal from the $\mathrm{AE}$ transducer was inputted to a personal computer through the $\mathrm{AE}$ tester. A wattmeter was installed in the motor, and power consumption was then measured. In addition, the output signal from the $\mathrm{AE}$ transducer was amplified by $54 \mathrm{~dB}$ using the $\mathrm{AE}$ tester, then high-pass filtered over $100 \mathrm{kHz}$; the average signal rectified in a half wave was then

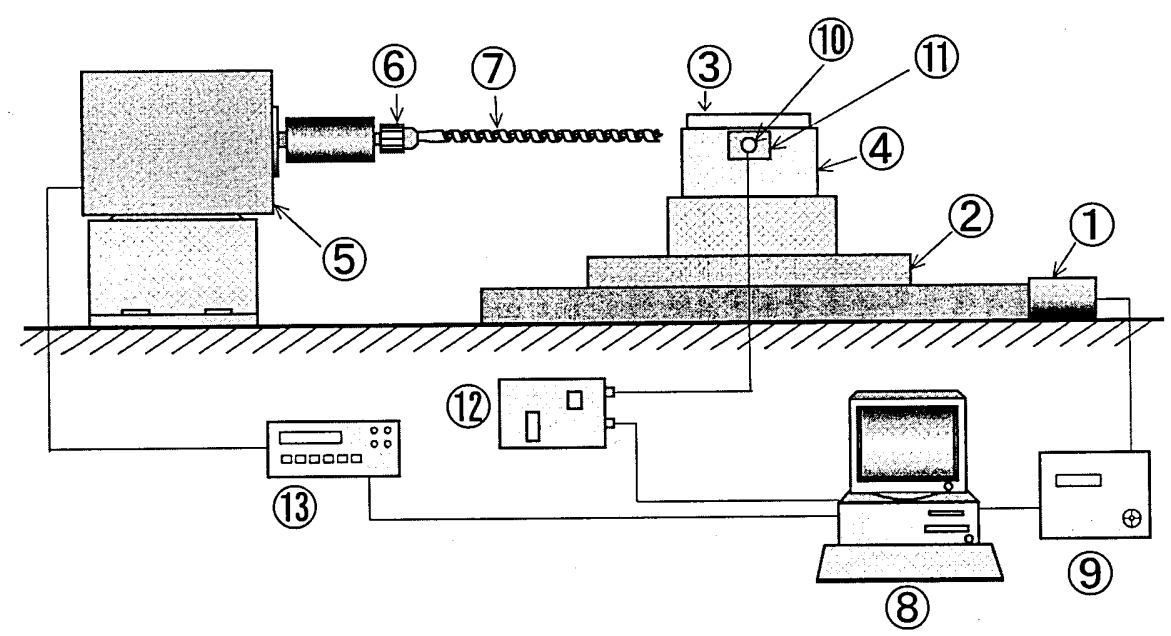

Fig. 1. Schematic diagram of the experimental apparatus.

Legend: (1) Pulse motor, (2) Stage, (3) Workpiece, (4) Vise, (5) Motor, (6) Chuck, (7) Bit,

(8) Personal computer, (9) Controller, (10) AE sensor, (11) Magnetic holder, (12) AE tester,

(13) Wattmeter 
sampled.

\section{Auger bits}

Auger bits had a spur edge, a cutting edge, and a center drill which had a feed-screw. In this study, auger bits that were killed a feed-screw by grinding were used as shown in Figure 2 (Banshoya et al., 2001). The tool material was alloy tool steel. The diameter was $9 \mathrm{~mm}$ and an overall length was $240 \mathrm{~mm}$. Bits in which the spur edge recessions reached to 100,200 and 400 microns by continuous boring of particleboard were prepared. In this test, these worn bits and a non-cutting bit were used.

(A)

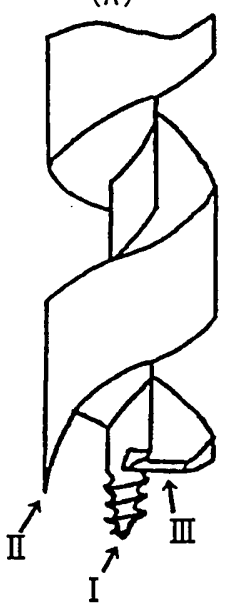

(B)

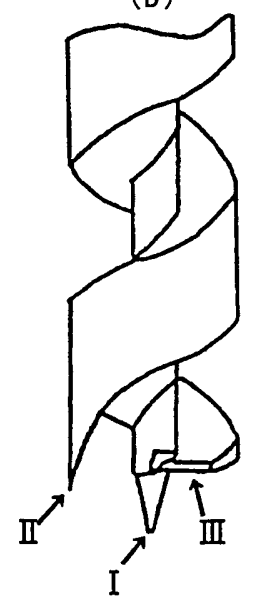

Fig. 2. Drawing of tools used in this experiment. Legend: I: Center drill, II: Spur edge, III: Cutting edge

\section{Work materials}

The work materials used in this test were Hemlock (air-dried specific gravity : 0.47, moisture content : 12.8\%). Workpiece A (Fig. 3A), which was assumed to be non knot, workpiece B (Fig. 3B), which was assumed to be loose knot and workpiece C (Fig. 3C), which was assumed to be live knot were prepared, respectively. In workpiece B, material that performed boring at a diameter of $12 \mathrm{~mm}$ was inserted in a position from 20 to $40 \mathrm{~mm}$ in the depth of the hole. In workpiece $\mathrm{C}$, Ramin (diameter : $12 \mathrm{~mm}$, air-dried specific gravity : 0.7 , moisture content : $10.6 \%$ ) of column type was buried under the loose knot of workpiece $\mathrm{B}$. Here, let $\alpha$ be the angle between the boring direction and annual ring, and $\alpha$ of all workpieces was measured as shown in Figure 4 . When $\alpha$ was positive, it meant that the direction of the annual ring was to the right of the boring direction. When $\alpha$ was 


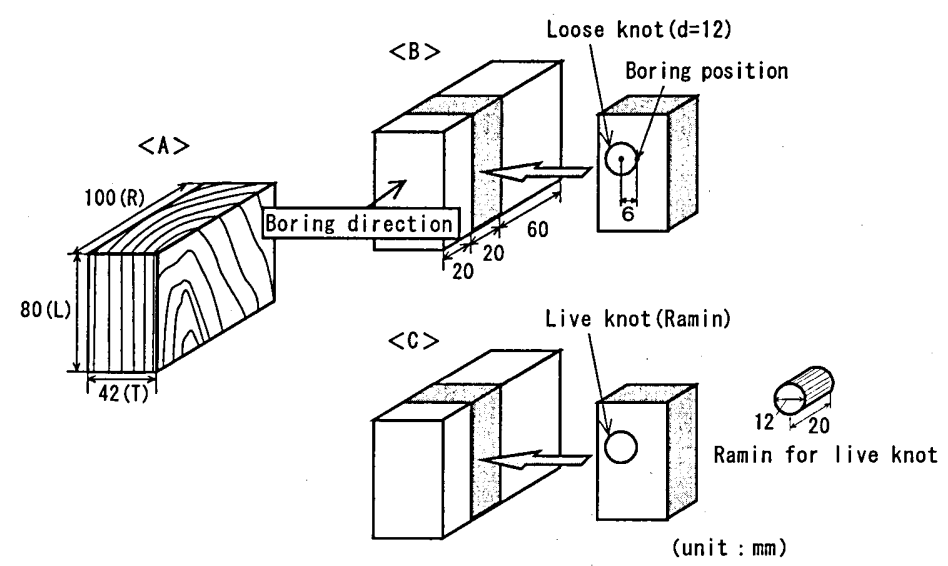

Fig. 3. Drawing of workpieces used in this expriment.

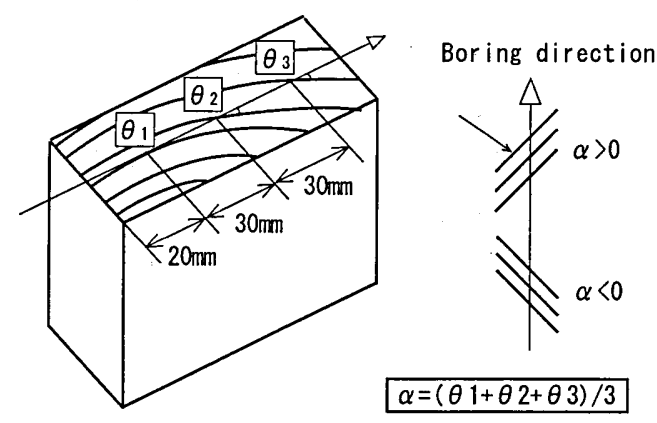

Fig. 4. Measuring method of $\alpha$.

negative, it meant that the direction of annual ring was to the left of the boring direction. The range of $\alpha$ of all workpieces used in this test were from -25.5 to 37.0 degrees.

\section{Deep boring conditions and measurement method}

The feed per revolution of $0.1,0.40 .7,1.0 \mathrm{~mm} / \mathrm{rev}$ were tested while keeping the spindle speed at $1700 \mathrm{rpm}$. In each experiment, through-hole borings of $100 \mathrm{~mm}$ in depth were performed, and were repeated three times per test condition. In the measurement of the axial deviation of the hole, the edge distance (Xin, Xout) and end distance (Yin, Yout) in the hole on the entrance and the exit side were measured by using image analysis software, as shown in Figure 5. The difference $(\Delta X, \Delta Y)$ in the distance between the entrance and the exit side was calculated, and the axial deviation of the hole was evaluated with these values. Therefore, when $\Delta X$ is positive, it means that the hole turns right with respect to the boring direction. When $\Delta X$ is negative, it means that the 


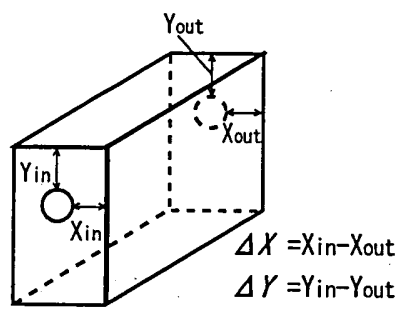

Fig. 5. Measuring method of axial deviation of hole.

hole turns left with respect to the boring direction. Moreover, when $\Delta Y$ is positive, it means that the hole bends up with respect to the boring direction. When $\Delta Y$ is negative, it means that the hole bends down with respect to the boring direction.

\section{RESULTS AND DISCUSSION}

\section{Axis deviation of hole}

The axis deviation of the holes in workpiece $A$, workpiece $B$, and workpiece $C$ are shown in Figures 6, 7, and 8 respectively as typical examples of the result. In the case of

$$
\text { 【a>0】 }
$$
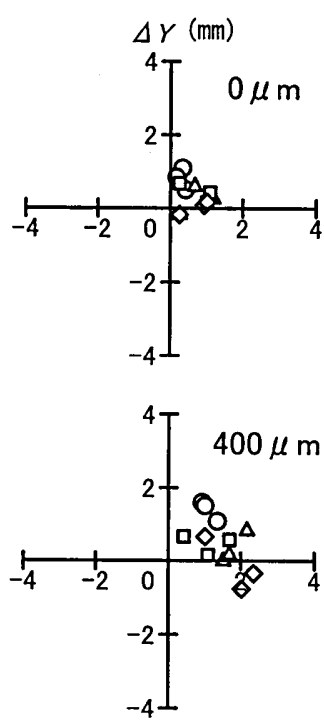

【 $\alpha<0 】$
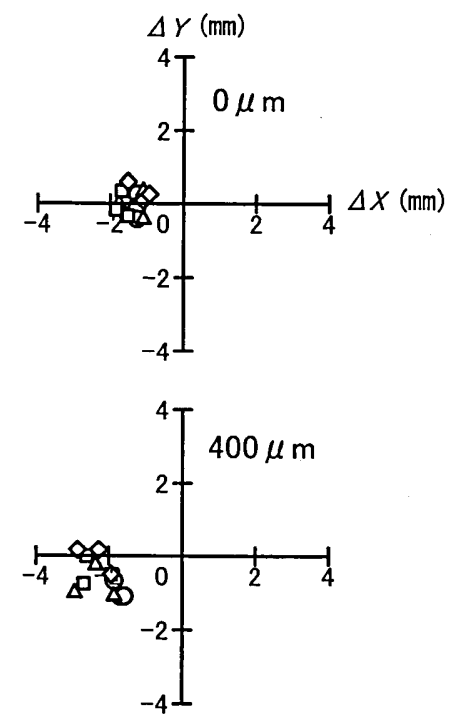

Fig. 6. Axial deviation of hole (workpiece A).

Legend: Feed per revolution (mm/rev)

$\bigcirc: 0.1, \triangle: 0.4, \square: 0.7, \diamond: 1.0$ 

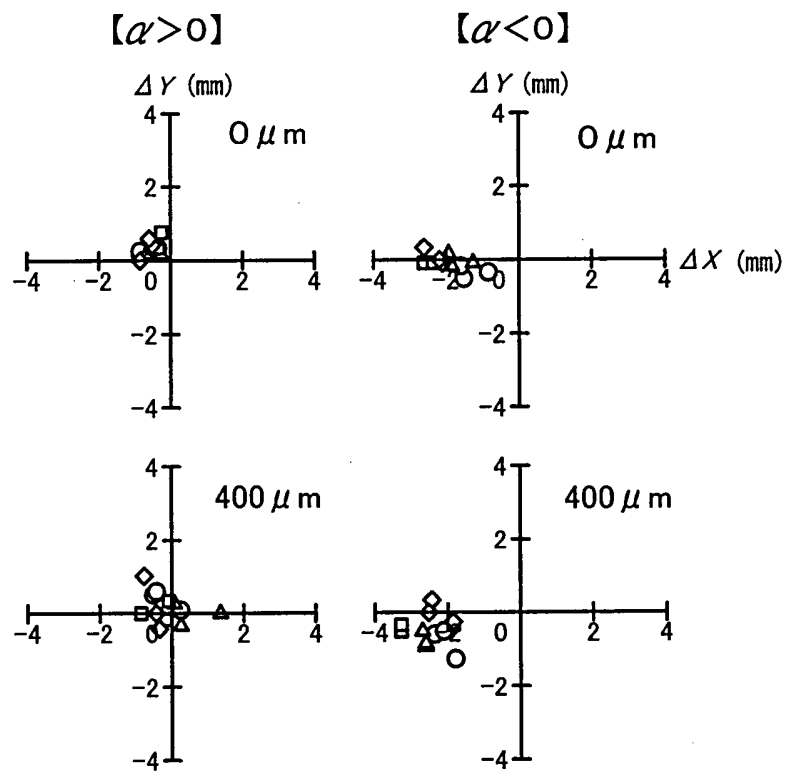

Fig. 7. Axial deviation of hole (workpiece B). Legend: Symbols are as shown in Fig. 6.

workpiece A (Fig. 6), $\Delta X$ had positive values when $\alpha$ was positive, and $\Delta X$ had negative values when $\alpha$ was negative. From these results, it was found that the hole deviated along the annual ring. $\Delta Y$ had smaller values than $\Delta X$, except for in one condition that in which the annual ring influences the axis deviation of the hole. Moreover, axis diviation of the holes became larger with increasing bit wear. The tendencies mentioned above were similar for workpiece B and workpiece C. In the case of workpiece B (Fig. 7), $\Delta X$ was nearly zero when $\alpha$ was positive, and $\Delta X$ had negative values when $\alpha$ was negative, and these negative values was larger than those for workpiece $A$. These results mean that many holes deviated great deal in the direction of the loose knot. This deviation is considered to occur when the cutting resistance becomes small in machine-boring to loose knot. However, axis deviation of the hole became small when $\alpha$ was positive, because the annual ring direction is the opposite direction to the position of the loose knot. In contrast, when $\alpha$ was negative, the axis deviation of the hole became large, because the annual ring direction is the same direction as the position of loose knot. Moreover, the axis deviation of the hole showed a tendency to increase with increasing bit wear when $\alpha$ was negative. However, when $\alpha$ was positive, the tendency was hardly recognized. In the case of workpiece $C$ (Fig. 8), the hole deviated along the annual ring, and the axis deviation of the hole was smaller than workpiece A when $\alpha$ was negative. In machine-boring to a live knot with large specific gravity, the cutting resistance became large, and the axis deviation of the hole was suppressed because the resistance acted on 

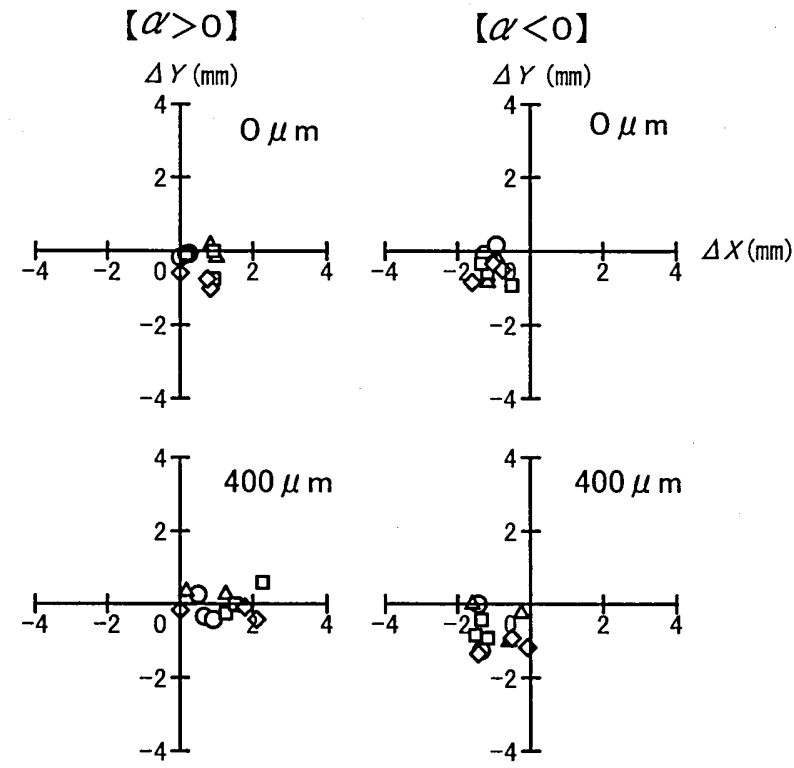

Fig. 8. Axial deviation of hole (workpiece C). Legend: Symbols are as shown in Fig. 6.

the direction of $\mathrm{X}$ axis. Moreover, the axis deviation of the hole became larger with increasing bit wear when $\alpha$ was positive. However, this tendency was hardly recognized when $\alpha$ was negative. All of the workpieces were almost unaffected by the feed per revolution.

\section{Waveforms of $\mathrm{AE}$ and power consumption}

The typical waveforms of $\mathrm{AE}$ and power consumption obtained in this test are shown in Figure 9. The $\mathrm{X}$ axis in these graphs showed the depth of the hole, and the time at which the point of the center drill entered into the workpiece was assumed to be $0 \mathrm{~mm}$. The section from 25 to $45 \mathrm{~mm}$ in the dept of the hole was assumed to be section. The section from 70 to $90 \mathrm{~mm}$ in the dept of the hole was assumed to be section. The waveforms of $\mathrm{AE}$ in workpiece $\mathrm{A}$ became larger within $5 \mathrm{~mm}$ in the depth of the hole after the center drill entered into the workpiece, and became constant on average after that. The waveforms of power consumption increased from a depth of $5 \mathrm{~mm}$ in the hole, and became constant after that. In workpiece $\mathrm{B}$, the waveforms of $\mathrm{AE}$ and power consumption within $25 \mathrm{~mm}$ in the depth of the hole showed a similar tendency to those of workpiece A. However, both waveforms decreased in section. For the other hand, both waveforms in workpiece $\mathrm{C}$ became larger in section. The difference in these tendencies depended on whether the workpiece had a knot or not. Therefore, it is clear that the processing of the knot can be monitored using waveforms of $\mathrm{AE}$ and power consumption. 

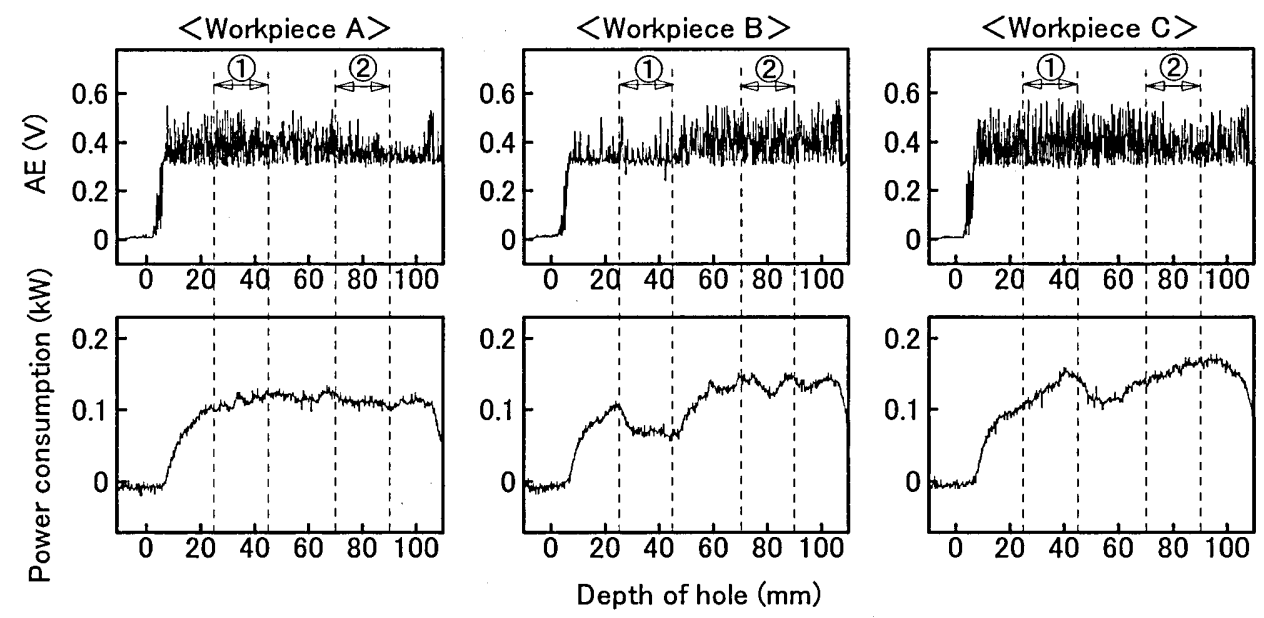

Fig. 9. Typical waveforms of $\mathrm{AE}$ and power consumption.

Notes: Workpiece B, $\alpha>0,0 \mu \mathrm{m}, 0.7 \mathrm{~mm} / \mathrm{rev}$

\section{Effect of bit wear on the average value of $\mathrm{AE}$ and power consumption}

The relationships between the average values of $\mathrm{AE}$, power consumption in the section from 70 to $90 \mathrm{~mm}$ within the hole and bit wear are shown in Figures 10 and 11. In all the workpieces, the average value of the $\mathrm{AE}$ were almost unaffected by the bit wear,

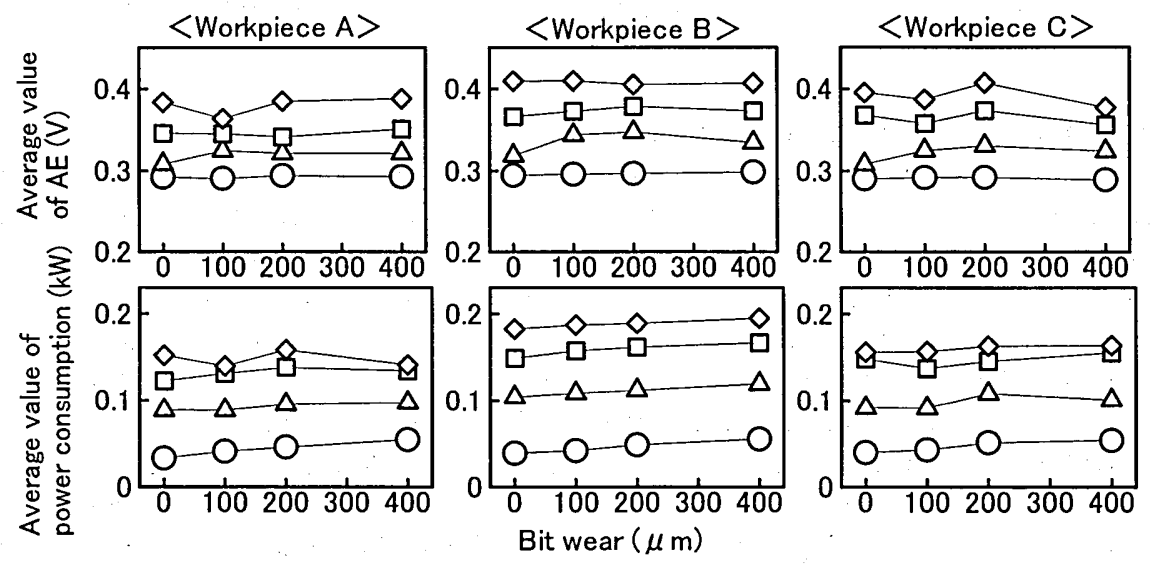

Fig. 10. Relationships between the average values of $\mathrm{AE}$, power consumption and bit wear $(\alpha>0)$.

Legend: Feed per revolution (mm/rev) $\bigcirc: 0.1, \triangle: 0.4, \square: 0.7, \diamond: 1.0$ 


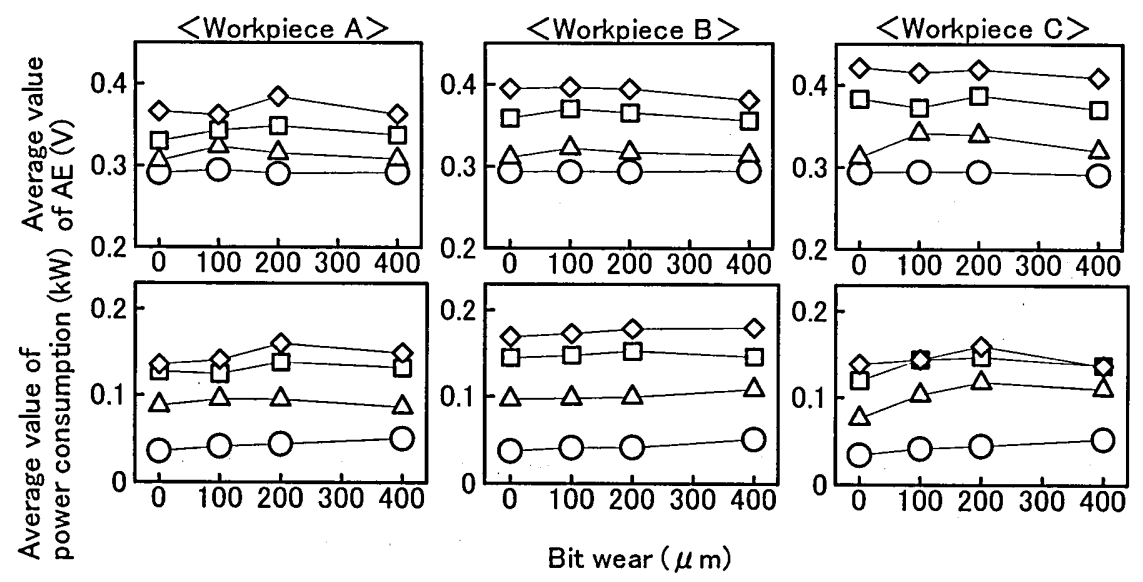

Fig. 11. Relationships between the average values of $\mathrm{AE}$, power consumption and bit wear $(\alpha<0)$. Legend: Symbols are as shown in Fig. 10.

but the average value of power consumption increased slightly by bit wear in some conditions. Moreover, the average values of $\mathrm{AE}$ and power consumption became larger with increasing feed per revolution.

\section{Relationships between AE, power consumption and axial deviation of hole}

Figure 12 shows the relationships between the average value of $\mathrm{AE}$, power consumption in the section from 70 to $90 \mathrm{~mm}$ within the hole in workpiece $\mathrm{A}$ and $\Delta X$, respectively. Thus, the average values of the $\mathrm{AE}$ and power consumption were almost unaffected by $\Delta X$. That is, it was clear that a correspondence between the axial deviation of the hole and the $\mathrm{AE}$ or power consumption was not recognized.
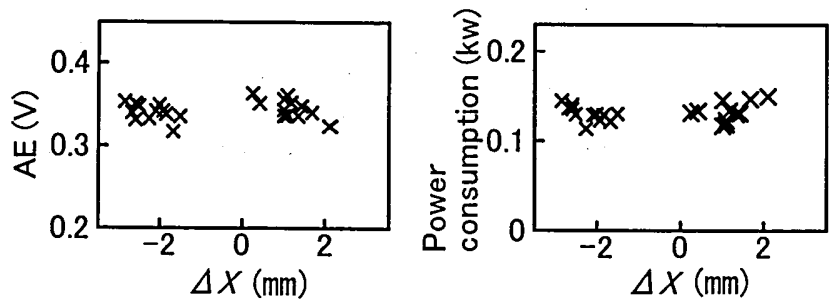

Fig. 12. Relationships between the average values of $\mathrm{AE}$, power consumption and $\Delta X$.

Notes: Workpiece A, Feed per revolution: $0.7 \mathrm{~mm} / \mathrm{rev}$ 


\section{CONCLUSIONS}

The objective of this study was to obtain basic information on axial deviation of the hole in the deep machine-boring of wood. In this experiment, the effects of knots and bit wear on axial deviation of hole were examined, and the acoustic emission (AE) and power consumption were also measured during the boring process. The main results obtained are as follows:

1) Axial deviation of the hole was affected by the annual rings and became larger with increasing bit wear.

2) In workpieces which had a loose knot, all deep holes deviated in the direction of the loose knot.

3) The average value of the $\mathrm{AE}$ and power consumption became larger with increasing feed per revolution.

4) A correspondence between axial deviation of the hole and the AE or power consumption was not recognized.

\section{REFERENCES}

Aguilera, A., P-J. Meausoone., P. Martin 2001 Surface Roughness and Acoustic Emission Measurements in Radiata Pine Planed Wood A Tool-Material Pairing Application. Proceedings of the 15th International Wood Machining Seminar (Los Angeles), 457-458

Banshoya, K., Ohuchi, T., Iwasaki, K 2001 Cutting Force in Machine Boring of Wood with Augar Bit: Lifting Force of Wood by Augar Bit and Safety Working. Hiroshima Journal of School Education, Vol. 7: $125-130$

Dornfeld, D. A., R. L. Lemaster 1982 Sensing of tool wear by acoustic emission. Proceedings of the Seventh International Wood Machining Seminar (Richmond), pp. 312-323

Kato, K., R. L. Lemaster 1991 Generation of acoustic emission during chip formation. Proceedings of the Tenth Intermational Wood Machining Seminar (Richmond), pp. 146-158

Murase, Y., IKE, K., Mori, M 1988 Acoustic Emission Monitoring of Wood Cutting I. Detection of tool wear by AE signals. Mokuzai Gakkaishi, 34(3): 207-213

Ohuchi, T., Suzuki, N., Murase, Y 2003 Acoustic Emission Characteristics and Trust in Machine boring of wood. Science Bulletin of the Faculty of Agriculture Kyushu University, 57(2): 161-168

Sadanari, M., Kitayama, S., Hattori, N., Segawa, K 1991 Relationships between Chip Formations and Acoustic Emissions during the Rectilinear Cutting of Wood. Mokuzai Gakkaishi, 37(5): 424-433

Tanaka, C., Nakao, T., Nishino, Y., Hamaguchi, T., Takahashi, A 1992 Detection of Wear Degree of Cutting Tool by Acoustic Emission Signal. Mokuzai Gakkaishi, 38(9): 841-846

Zhao, C., Tanaka, C., Nakao, T., Nishino, Y., Takahashi, A., Ikeda, S 1993 Adaptive Control Optimization in Band Sawing III. Effects of depth workpiece and moisture content on acoustic emission signals, cutting force, sawed surface roughness and band-saw deviation. Mokuzai Gakkaishi, 39(2): $138-143$ 